DOI: 10.20472/IAC.2017.33.020

\author{
ANDRÉ W. HEINEMANN \\ University of Bremen, Germany \\ HANNA KOTINA \\ Kyiv National Economic University, Ukraine \\ MARYNA STEPURA \\ Kyiv National Economic University, Ukraine
}

\title{
AN INTERDISCIPLINARY VIEW ON TAX REVENUE ESTIMATES AND FORECASTS AND ITS IMPACTS ON A MULTILEVEL PUBLIC BUDGET SYSTEM
}

\begin{abstract}
:
While tax revenue forecasts are required for the public budget planning and execution process, the frameworks and accuracy of tax revenue forecasts are crucial for economic analysis of public budgets in multilevel systems. Insufficient and defective tax revenue forecasts can lead to budget problems as well as budget interdependencies in multilevel systems. The determination of budget revenues amount, which can actually be carried out, needs to estimate the forecast of tax revenues reasonably and accurately. Adequacy and feasibility of relevant indicators depend on the assessment of the state, trends and forecasting of economic and social development, stability and progressiveness of the current legislation, the forms and methods of tax mobilization, the level of fiscal culture and other factors. The role of tax revenue forecasting is enhanced significantly. Fiscal equalization schemes, grant systems and bailout rules have to take into account in the case of problems with the accuracy of tax revenue forecasts. If tax revenues forecasts in the medium-term are upward biased, the institutional setting can be an explanation for forecasts errors (Breuer 2014). However, over-optimistic as well as under-optimistic forecasts influence budgeting and budget targets.

The present paper deals with the conditions and institutional frameworks for accuracy of tax revenue forecasts, especially in a medium-income and a high-income country. First, we present a literature review on tax revenue forecast and the importance of institutional performance for accurate tax revenue forecasts. Thereby, empirical studies to explain forecasts errors will be analyzed. In a comparison of two countries, the second session describes the institutional setting for tax revenue forecasts and the procedures in the Ukraine and Germany and shows the methods, actors and institutional mechanisms in these different multilevel systems. The analysis focusses on the degree of decentralization in both countries and legal equalization schemes. We show some determinants of tax revenue forecast errors and discuss the impacts and consequences for budgetary planning and budget managing in multilevel systems.

Our findings point out the importance of fiscal governance in multilevel systems if tax revenue forecasts are influenced by many determinants in specific ways that makes revenue forecast difficult. Multilevel fiscal governance is required to solve problems in tax revenue forecasts and budgeting in decentralized systems. Additionally, the knowledge on taxpayer's behavior (households, employees, consumer, firms) under conditions of globalization of taxation is underestimated at the present, but is needed for the improvement of public budget managing processes.
\end{abstract}




\section{Keywords:}

Tax estimates, Tax forecasts, Budget planning, Multilevel governance

JEL Classification: $\mathrm{H} 11, \mathrm{H} 70, \mathrm{H} 77$ 